University of Nebraska - Lincoln

DigitalCommons@University of Nebraska - Lincoln

Faculty Publications: Department of

Entomology

Entomology, Department of

2001

Molecular phylogeny of Diabrotica beetles (Coleoptera:

Chrysomelidae) inferred from analysis of combined mitochondrial and nuclear DNA sequences

\author{
Thomas L. Clark \\ University of Missouri \\ Lance J. Meinke \\ University of Nebraska-Lincoln, Imeinke1@unl.edu \\ John E. Foster \\ University of Nebraska-Lincoln, john.foster@unl.edu
}

Follow this and additional works at: https://digitalcommons.unl.edu/entomologyfacpub

Part of the Entomology Commons, and the Genetics and Genomics Commons

Clark, Thomas L.; Meinke, Lance J.; and Foster, John E., "Molecular phylogeny of Diabrotica beetles (Coleoptera: Chrysomelidae) inferred from analysis of combined mitochondrial and nuclear DNA sequences" (2001). Faculty Publications: Department of Entomology. 633.

https://digitalcommons.unl.edu/entomologyfacpub/633

This Article is brought to you for free and open access by the Entomology, Department of at DigitalCommons@University of Nebraska - Lincoln. It has been accepted for inclusion in Faculty Publications: Department of Entomology by an authorized administrator of DigitalCommons@University of Nebraska - Lincoln. 
Published in Insect Molecular Biology 10(4), pp. 303-314.

Copyright ( 2001 Blackwell Science Ltd. Used by permission.

Submitted October 21, 2000, accepted February 28, 2001.

PMID: 11520353

\title{
Molecular phylogeny of Diabrotica beetles (Coleoptera: Chrysomelidae) inferred from analysis of combined mitochondrial and nuclear DNA sequences
}

\author{
T. L. Clark, L. J. Meinke, and J. E. Foster \\ Department of Entomology, University of Nebraska-Lincoln, Lincoln, Nebraska, USA \\ Corresponding author - Thomas L. Clark, 205 Curtis Hall, Department of Entomology, University of \\ Missouri, Columbia, Missouri 65211-7020, USA
}

\begin{abstract}
The phylogenetic relationships of thirteen Diabrotica (representing virgifera and fucata species groups) and two outgroup Acalymma beetle species (Coleoptera: Chrysomelidae) were inferred from the phylogenetic analysis of a combined data set of $1323 \mathrm{bp}$ of mitochondrial DNA (mtDNA) cytochrome oxidase subunit 1 (COI) and the entire second internal transcribed spacer region (ITS-2) of nuclear ribosomal DNA of 362 characters. Species investigated were $D$. adelpha, $D$. balteata, $D$. barberi, $D$. cristata, D. lemniscata, $D$. longicornis, $D$. porracea, $D$. speciosa, $D$. undecimpunctata howardi, $D$. u. undecimpunctata, $D$. virgifera virgifera, D. v. zeae, D. viridula, and outgroup $A$. blandulum and $A$. vittatum. Maximum parsimony (MP), minimum evolution (ME), and maximum likelihood (ML) analyses of combined $\mathrm{COI}$ and ITS-2 sequences clearly place species into their traditional morphological species groups with MP and ME analyses resulting in identical topologies. Results generally confer with a prior work based on allozyme data, but within the virgifera species group, $D$. barberi and $D$. longicornis strongly resolve as sister taxa as well as monophyletic with the neotropical species, $D$. viridula, $D$. cristata and $D$. lemniscata also resolve as sister taxa. Both relationships are not in congruence with the prior allozyme-based hypothesis. Within the fucata species group, $D$. speciosa and $D$. balteata resolve as sister taxa. Results also strongly supported the $D$. virgifera and $D$. undecimpunctata subspecies complexes. Our proposed phylogeny provides some insight into current hypotheses regarding distribution status and evolution of various life history traits for Diabrotica.
\end{abstract}

Keywords: Diabrotica, rootworms, mtDNA, cytochrome oxidase subunit I, ITS-2, phylogeny 


\section{Introduction}

The genus Diabrotica represent a large group of phytophagous beetles (Coleoptera: Chrysomelidae: Galerucinae: Luperini: Diabroticites) composed of 338 valid species (Wilcox, 1972). The genus is historically neotropical, although $D$. virgifera virgifera LeConte has been recently introduced as a pest of maize, Zea mays L., in Europe (Camprag \& Baca, 1996), with the greatest diversity of species in tropical areas (Smith, 1966; Krysan, 1986; Krysan \& Smith, 1987). Diabrotica is generally separated into three species groups: signifera, fucata and virgifera, with the latter two containing identified pest species, which may explain why these groups have been disproportionately studied (Krysan, 1986). The virgifera species group is composed of twenty-one known species with the remainder in the fucata (305 species) and signifera (eleven species) species groups (Wilcox, 1972; Krysan \& Smith, 1987).

Their pest status (fifteen species and subspecies are reported as pests of sixty-one different crops (Krysan, 1986)), has meant that Diabrotica species have been the focus of numerous studies on life history (Metcalf, 1979; Branson \& Krysan, 1981; Krysan, 1982), species distribution (Smith, 1966; Krysan, 1986; Krysan \& Smith, 1987), reproductive isolation (Krysan \& Guss, 1978; Krysan et al., 1983, 1986; Guss et al., 1982, 1983a, 1983b, 1984, 1985; Giordano et al., 1997) and host-plant relationships (Metcalf, 1979; Branson \& Krysan, 1981; Yaro \& Krysan, 1986). For example, Branson \& Krysan (1981) and Krysan (1982) suggested that species in the fucata species group are multivoltine and polyphagous while species in the virgifera species group are univoltine and oligophagous (or monophagous) with species group specific differences being attributed to host plant availability and climate. From a evolutionary and chemical ecology perspective many Diabrotica and related Diabroticites such as Acalymma have been the subject of many studies. Metcalf $(1979,1986)$ reviewed the evolution and chemical ecology of Diabroticite affinity toward triterpene cucurbitacins found in the plant family Cucurbitaceae. Various aspects of this research was embraced as it was discovered that insecticides could be mixed with selected cucurbitacins for control of pest Diabrotica and Acalymma (Metcalf et al., 1987; Weissling et al., 1989; Weissling \& Meinke, 1991). Beyond cucurbitacins, Branson \& Krysan (1981) presented evidence for an evolutionary relationship between D. virgifera and Z. mays as well as anecdotal evidence for associations of other Diabrotica, particularly Nearctic species, with native grasses. 
Krysan et al. (1989) inferred evolutionary relationships of selected Diabrotica using allozyme data and resolved nine species into their respective clades. These authors provided evidence that closely related sympatric Diabrotica in the virgifera species group have stronger reproductive barriers in terms of reduced pheromone cross attractance than allopatric species within the same group. While this work provided an essential foundation in the study of phylogenetic relationships within Diabrotica, the authors also noted that it may have lacked resolution in the deepest nodes of the resulting phenogram because D. cristata (Harris) and $D$. longicornis (Say) were grouped as sister taxa in a monophyletic group with $D$. barberi, rather than the morphological sibling species $D$. longicornis and $D$. barberi Smith and Lawrence.

There is a high degree of similarity within Diabrotica even beyond the sibling and subspecies levels. For example, Krysan et al. (1989) observed that while they were able distinguish $D$. cristata and $D$. lemniscata LeConte neither species has phylogenetically informative characters. The analysis of DNA sequences may help solve this problem by providing additional phylogenetically informative characters. This is especially true in Diabrotica because this genus of beetles is characterized by morphological similarity, a problem that is common within this genus as well as other genera in the subfamily Galerucinae (Wilcox, 1965).

The use of mitochondrial DNA (mtDNA) sequence data has become a proven standard for many phylogenetic studies (Caterino et al., 2000). Among the many mitochondrial genes that have been studied, subunit I of the cytochrome oxidase gene (COI) has become a standard for phylogenetic inference of many insect groups (Lunt et al., 1996). Examples include but are not limited to Lepidoptera at the species level (Caterino \& Sperling, 1999), Hymenoptera at the subgeneric level (Koulianos, 1999), and Orthoptera at the intraspecific level (Lunt et al., 1998) to name a few. Given the proven utility of $\mathrm{COI}$ to resolve phylogenetic relationships at many taxonomic levels, we believed the use of this gene was appropriate given there were five classification categories represented in this study (genus, species within a genus, species within a clade, sibling species, and subspecies).

The internal transcribed spacers of nuclear ribosomal DNA have been used extensively for intra- and interspecific relationships in closely related and cryptic species of insects and arthropods (Porter \& Collins, 1991; Paskewitz et al., 1993; Navajas et al., 1998). While lack of interspecific variation (Kuperus \& Chapco, 1994) or high intraspecific variation may limit the use of ITS regions in phylogenetic studies (Vogler \& DeSalle, 1994), 
other studies have shown that these regions do indeed have phylogenetic utility (Miller et al., 1996; Schilthuizen et al., 1998; Depaquit et al., 2000). Because some of the taxa selected in this study are closely related with some cryptic morphological features, we also explored the phylogenetic resolving utility of the ITS-2 region.

In this study, we begin the process of constructing a phylogeny of the genus Diabrotica by considering nine of the ten species that are known to occur in the United States as well as selected species that inhabit Central and South America. Presented is the first phylogenetic hypothesis of Diabrotica based upon DNA sequence data from mitochondrial (COI) and nuclear sources (ITS-2). The purpose of this study was to provide an initial step in understanding the evolutionary history of Diabrotica based on DNA sequences of this closely related, widespread and economically important group of beetles for which little phylogenetic information exists.

\section{Results}

\section{COI sequence variation}

The length of the sequenced COI fragment was $1323 \mathrm{bp}$ for all Diabrotica evaluated and $1320 \mathrm{bp}$ for both Acalymma species. The difference between the genera was the deletion of a codon between positions 1312 and 1314 of the Diabrotica fragment, which codes for a serine residue. The adjoining portion of the t-RNA-Leu gene that was $21 \mathrm{bp}$ for all species represents the 3 ' priming region for the $\mathrm{COI}$ fragment and was not subject to further analysis. Of the $1323 \mathrm{COI}$ characters 434 were variable between taxa, of which 303 were parsimony informative. PTP tests indicated significant phylogenetic structure $(P=0.0002)$. Table 1 lists base composition for each $\mathrm{COI}$ codon position where nucleotide frequencies were biased toward $\mathrm{A}+$ $\mathrm{T}$, averaging $69.78 \%$. This bias was also apparent at the respective codon positions, with third position codons having the greatest bias at $89.48 \% \mathrm{~A}$ $+T$. No significant differences were detected between taxa in terms of base composition $\left(\chi^{2}=6.62\right.$ (d.f. $\left.\left.=42\right), P=1.00\right)$. The transition/transversion ratio (estimated by maximum likelihood on a $\mathrm{NJ}$ tree) for $\mathrm{COI}$ considering all codon positions is 2.06 .

\section{ITS-2 sequence variation}

The entire ITS-2 with portions of flanking 5.8S and 28S rRNA genes were successfully sequenced for all taxa. The boundaries of ITS-2 were determined by these highly conserved flanking regions (Navajas et al., 
1998). The 3 ' portion $5.8 \mathrm{~S}$ was $155 \mathrm{bp}$ while the $5^{\prime}$ portion of $28 \mathrm{~S}$ was $50 \mathrm{bp}$ for all taxa. Not a single bp change (transition, transversion, or indel) for either flanking region was observed. Thus, these conserved regions were excluded from further consideration. The length of the entire ITS-2 varied from $323 \mathrm{bp}$ (D. adelpha) to $352 \mathrm{bp}$ (D. v. virgifera and D. v. zeae). However, alignment of all sequences yielded 362 characters when considering insertion/deletion (indel) events of which eighty-nine were variable with fifty-five of these characters being parsimony informative. PTP tests indicated significant phylogenetic structure $(P=0.0002)$. Indels ranged from single bp events to $10 \mathrm{bp}$ deletions, in total forty-seven sites out of 362 had at least one taxa with an indel (Table 1). ITS-2 nucleotide frequencies were also biased toward $\mathrm{A}+\mathrm{T}$ averaging $66.9 \%$ (Table 1). No significant differences were detected between taxa in terms of base composition $\left(X^{2}=12.83\right.$ (d.f. $\left.=42\right), P=1.00$ ). The transition/transversion ratio (estimated by maximum likelihood on a NJ tree) for ITS-2 considering all sites is 1.40 .

\section{Nucleotide distances}

Nucleotide distances corrected using Tamura and Nei's (1993) method among all taxa range from $0.3 \%$ to $23.7 \%$ for the ITS-2 and $0.5 \%$ to $18.4 \%$ for COI (Table 2). Inter-generic differences ranged from $13.1 \%$ to $23.7 \%$ for ITS-2 and $13.5 \%$ to $18.4 \%$ for COI (Table 2). Distances between the morphologically assigned species groups range from $5.5 \%$ to $8.5 \%$ for ITS2 and $12.4 \%$ to $15.7 \%$ for COI (Table 2). Within the virgifera species group distances range from $0.3 \%$ to $3.2 \%$ for ITS-2 and $1.1 \%$ to $10.7 \%$ for COI (Table 2). Between the fucata species distances ranged from $0.6 \%$ to $3.7 \%$ for ITS-2 and $0.5 \%$ to $13.6 \%$ for COI (Table 2 ).

\section{Combining COI and ITS-2}

The partition homogeneity test between COI and ITS-2 sequences did not reject the null hypothesis that either data set was significantly different from a random partition of pooled data $(P=0.32)$. Thus, we combined both data sets for the phylogenetic analyses shown in this manuscript. The combined data set is comprised of 1685 total characters of which 524 were variable and 359 were parsimony informative. The PTP test detected significant phylogenetic structure in the combined data set $(P=0.0002)$.

MODELTEST selected the general time reversible model including the proportion of invariable sites and gamma distribution for rate variation among sites (GTR + I + G) (Lanave et al., 1984; Yang, 1994; Gu et al., 1995) as the best fit for ME and ML phylogenetic analyses of the combined data. 
Rate matrix parameters estimated on the neighbour-joining tree are: $R(a)$ $[A-C]=3.20, R(b)[A-G]=8.21, R(c)[A-T]=3.73, R(d)[C-G]=1.26, R(e)[C-$ $\mathrm{T}]=25.19, \mathrm{R}(\mathrm{f})[\mathrm{G}-\mathrm{T}]=1.00$. The proportion of invariable sites $(\mathrm{I})$ and the gamma shape distribution parameter $(G)$ are approximated at 0.48 and 0.54 , respectively.

\section{Phylogenetic analysis}

While describing trees that were inferred from different analyses, we considered bootstrap values of $70 \%$ or greater as strong, between 50 and $70 \%$ as moderate, and below $50 \%$ as weak (Hillis \& Bull, 1993). Unweighted parsimony analysis of the combined data set results in a single tree of 1154 steps (consistency index (C.I.) $=0.609$, retention index (R.I.) $=0.584)$ (Fig. 1). Results from the separate analyses of COI and ITS-2 data are not in conflict and are not presented here for simplicity. The same tree was recovered when transitions at third codon positions of the $\mathrm{CO}$ gene partition of the combined data set were down-weighted by a factor of two. Likewise, an identical tree topology was obtained under ME analysis using the GTR + I $+\mathrm{G}$ model described previously (Fig. 2). The topology of both analyses received moderate to strong support at most nodes, as suggested by bootstrap values with a couple exceptions. A subclade with $D$. porracea being monophyletic with the $D$. virgifera subspecies is relatively weak for both ME and MP analyses (Figs 1 and 2). ML analysis results in a similar topology as MP and ME but differs in that the moderately supported virgifera species group subclade $(D$. lemniscata, $D$. cristata; $D$. porracea; $D$. v. virgifera, D. v. zeae), was absent (Fig. 3). All analyses (Figs 1-3) clearly differentiate both morphological (virgifera and fucata) species groups, although bootstrapping of the ME analysis indicates only moderate bootstrap support (56\%) for the fucata species group (Fig. 2). The topology of the fucata species group was identically supported by all analyses. Additionally, all sister taxa and subspecies groupings as well as the monophyletic placement of $D$. viridula with the sister taxa, $D$. barberi and $D$. longicornis, received strong bootstrap support for all analyses (Figs 1-3).

\section{Discussion}

\section{Data analysis}

Both COI and ITS-2 sequences display similar divergence patterns between the taxa and have significant phylogenetic structure. It is interesting that the data partitions are not conflicting based on the partition homogeneity 
test considering that they come from different sources, evolve at different rates, and have quite different properties. For example, Navajas et al., 1998 reported that ITS-2 sequences appear to evolve 2.5 times faster than COI sequences in five Tetranychus species. Despite potential differences, we consistently recovered compatible trees among the data partitions, which also suggests that the models used to analyze the data were adequate in recovering the correct phylogenetic signal for the taxa examined (Miyamoto \& Fitch, 1995). While we chose to combine the data sets, the issue of combining data for phylogenetic analysis is debatable without a current consensus (Bull et al., 1993; de Queiroz et al., 1995; Miyamoto \& Fitch, 1995; Huelsenbeck et al., 1996). Considering that partition homogeneity tests were not significant, it is most likely that the combined data set maximizes the amount of information obtained while yielding the correct trees (Vogler \& Welsh, 1997; Chippindale et al., 1999).

Two different approaches to parsimony analysis; equal weighting and differential weighting of transitions at third codon positions of the $\mathrm{COI}$ gene, were applied to the combined data. Differential weighting was done with the intention of down-weighting the potential misleading effect of transitions that may accumulate at high frequencies in third codon positions (Meyer, 1994; Huang et al., 2000). Both approaches resulted in no topological differences. ME analysis based on the GTR + I + G model, which allows for differing substitution ratios and among site variability proportion, also identically supports the topology acquired in the different parsimony analyses. $M L$ based on the same model $(G T R+I+G)$ results in some minor topological differences in the virgifera species group from MP and $\mathrm{ME}$ that are not well supported in those analyses as well. Despite these minor differences, it is our opinion that we have entered a zone of high confidence estimation because we are beyond 1000 + sequence characters, which increases the chances of recovering the correct phylogenetic tree (Hillis et al., 1994a, 1994b). However, stronger resolution will most likely not be achieved until additional Diabrotica species are added to future studies.

\section{Comparison with a prior phylogenetic study and fit with information- based hypotheses}

All phylogenetic estimates presented in this study support traditional morphologically based assignments of the fucata and virgifera species groups, with the latter receiving the strongest support. This was not surprising because the virgifera species group has received the most taxonomic study, with Krysan \& Smith (1987) separating it from the rest of Diabrotica by examining sclerite shape on male genitalia as well as five 
external characters. Smith \& Lawrence (1967) and Wilcox (1972) have made important contributions in assigning other Diabrotica to the fucata species group but additional work is necessary to clarify morphological relationships.

Our results generally concur with Krysan et al.'s (1989) phenogram based on allozymes, especially considering the placement of species into their respective species groups. However we are not in congruence regarding their proposal of a monophyletic Nearctic species complex (D. cristata, $D$. longicornis and $D$. barberi) with $D$. cristata and $D$. longicornis regarded as sister taxa. Analyses of the combined sequences in our study place the morphological sibling species $D$. barberi and $D$. longicornis as sister taxa These results were not unexpected as other studies have reported a high degree of similarity between $D$. barberi and $D$. longicornis. For example, Krysan et al. (1983) reported that a discriminant analysis of fourteen morphometric characters failed to completely discriminate between $D$. barberi and $D$. longicornis. Moreover, examination of $D$. barberi and $D$. longicornis genitalia and spermathecae, characters which have proven reliable for distinguishing most Diabrotica, revealed no discriminating features between these two species (Krysan et al., 1983; Krysan \& Smith, 1987). Meanwhile, our analyses consistently placed $D$. cristata as sister with D. lemniscata, albeit a longer distance sister relationship. Reproductive isolation due to a lack of sex pheromone cross-attractance is one mechanism that closely related sympatric Diabrotica may use as a hybridization barrier (Krysan et al., 1989). We are in congruence with Krysan et al. (1989) regarding this aspect, because both sister taxa relationships, $D$. barberi-D. longicornis and $D$. cristata-D. lemniscata, proposed in our analyses are not pheromonally cross-attractive (Guss et al., 1984, 1985; Krysan et al., 1986).

Considering distribution status, D. barberi, D. longicornis, and D. cristata are the only Diabrotica species that are entirely Nearctic (Krysan \& Smith, 1987 ), yet both $D$. longicornis and $D$. cristata are geographically sympatric with D. lemniscata in Northern and central Mexico and the south-western United States (Krysan \& Smith, 1987). Likewise, D. porracea, D. v. virgifera and $D . v$. zeae are distributed within Nearctic and Neotropical regions and are geographically sympatric with the Nearctic species at several localities (Krysan \& Smith, 1987). The results presented in this study show no clear geographical pattern regarding phylogenetic placement of species. For example, all analyses support a monophyletic grouping of $D$. viridula, a Neotropical species, with Nearctic D. barberi and D. longicornis. Thus, 
geographical range may not be a good characteristic of support for an entirely Nearctic subclade as was presented by Krysan et al. (1989).

It is also difficult to make assumptions about phylogenetic placement of Diabrotica species in terms of habitat especially when considering relationships with adult host plants. For example, one argument for a common adult habitat is collection of beetles on the same host plant. This becomes questionable on cucurbits given the vestigial condition of Diabrotica attraction toward plants containing cucurbitacins (Metcalf et al., 1980), because this condition allows for the possibility to collect many Diabrotica on the same plant (even the same bloom) at a given point in time. The authors and their colleagues have collected all five species of Diabrotica (D. barberi, D. longicornis, D. cristata, D. v. virgifera and $D$. $u$. howardi) that occur in Nebraska on a single C. foetidissima plant (Golden, 1990; T. L. Clark and L. J. Meinke, unpublished data). Beyond curburbit association, species such as $D$. cristata, D. barberi, D. longicornis and $D$. $v$. virgifera have been collected as adults on a variety of prairie forbs such as sunflower, Helianthus spp.; smartweed, Polygonum spp.; and amaranth, Amaranthus spp. This may occur when preferred pollen sources are depleted. For example, D. barberi adults feed on pollen and succulent reproductive tissues of $Z$. mays during their ovipositional period (Krysan, 1999), however Cinereski \& Chiang (1968) observed that these beetles switch to alternate pollen sources outside the maize habitat as their ovipositional period exceeds the availability of maize pollen. Thus, the choice of adult host may actually be more of an opportunistic survival strategy rather than an indicator for an evolutionary relationship or a phylogenetic support character. In defense of habitat choice, $D$. longicornis, $D$. cristata, $D$. lemniscata, and $D$. barberi (historically, before the switch to maize) are all found as adults in ecosystems where perennial grasses are a permanent feature (Branson \& Krysan, 1981; Krysan \& Smith, 1987). It has also been hypothesized that virgifera clade ancestor evolved as a specialist on the roots of certain grasses (Branson \& Krysan, 1981; Krysan \& Smith, 1987). However, little is known about which grass species are actually utilized. Until more information is gained on larval host preferences or female oviposition choice, as suggested by $D$. cristata emergence on the perennial grass Andropogon gerardii Vitman (Yaro \& Krysan, 1986), treatment of Diabrotica habitat (especially for adults) must be taken with caution when considering it as a support character for phylogenetic resolution.

Related to larval food availability, the adaptation of egg diapause during unfavorable conditions such as dry seasons or seasonal cold periods when 
specific grass roots are unavailable is hypothesized to have evolved in a virgifera clade ancestor (Krysan, 1982). Because this life history trait has been exclusively observed in the virgifera species group, D. barberi, $D$. cristata, D. lemniscata, D. longicornis, D. v. virgifera and D. v. zeae (Krysan, 1982), it may indeed have evolved from a univoltine ancestor. Interestingly, three reported virgifera species group taxa, including two examined in this study $(D$. viridula and $D$. porracea), may have a multivoltine life cycle (Krysan \& Smith, 1987; Eben \& Barbercheck, 1996; Eben, 1999). This suggests that multivoltinism may have evolved independently from a univoltine progenitor species or that the progenitor was multivoltine with egg diapause evolving as given virgifera species group taxa colonized regions with alternating wet and dry seasons and/or temperate climates. The answer to this question most likely will not be known until more taxa are added to a future phylogenetic study complemented with voltinism information, which is currently lacking for most virgifera group species particularly those from Neotropical regions.

Within the fucata species group all analyses strongly supported the undecimpunctata subspecies. This was expected, as both subspecies respond identically to the sex pheromone 10-methyl-2-tridecanone (Guss et al., 1983b), and have similar life histories albeit in different geographical regions (Smith, 1966; Smith \& Michelbacher, 1949). These subspecies are part of a subspecies complex that also includes $D$. $u$. tenella LeConte and D. u. duodecimpunctata F., all of which occur in different geographical areas within North America separated by a series of mountain ranges and ecological zones (Krysan, 1986). The analysis of these subspecies with a biogeographical component would be a worthwhile and interesting study considering the pest status of this complex. The monophyly of $D$. speciosa and $D$. balteata was interesting. $D$. balteata is a cosmopolitan pest that ranges throughout Central America and Mexico into the Southern United States where its range is limited by an inability to survive subfreezing temperatures (Pitre \& Kantack, 1962; Saba, 1970; Krysan, 1986). D. speciosa apparently fills the same pest niche as $D$. balteata but in South America (Krysan, 1986). Chuman et al. (1987) isolated the sex pheromone, 6,12dimethylpentadcan-2-one, for $D$. balteata but to-date the $D$. speciosa pheromone has not been characterized. It would be of interest to examine if these species are isolated by sex pheromones or if they have a similar pheromonal structure. For example, some species of Diabrotica that have recently become sympatric due to agricultural practices, such as $D$. barberi and D. v. virgifera on maize in the North Central United States (Krysan \& 
Smith, 1987), display certain degrees of sex pheromone cross attractance (Guss et al., 1985).

\section{Possible insight into an evolutionary hypothesis}

It has been hypothesized that Diabroticites such as Diabrotica and Acalymma and their Old World galerucine counterpart Aulacophora evolved with Cucurbitaceae as evidenced by a similar affinity toward cucurbit hosts (Metcalf, 1979). Possible factors selecting for this association include protection against predators (Ferguson \& Metcalf, 1985; Nishida \& Fukami, 1990), entomopathogenic nematodes (Eben \& Barbercheck, 1997), and fungi (Brust \& Barbercheck, 1990; Tallamy et al., 1998) as well as reproductive success via sequestration of bitter tasting cucurbitacins to eggs (Ferguson et al., 1985). While these factors most certainly promote an evolutionary relationship, the extent to which various Diabroticite species groups and species within groups utilize cucurbits is intriguing and poses possibilities for co-evolutionary study. For example, between the Diabroticite genera, Acalymma and Diabrotica, an interesting hierarchy exists when considering utilization of cucurbit hosts. Acalymma spp. are dependent upon Cucurbitaceae as adult and larval hosts (Smith, 1966); fucata species group taxa can utilize various cucurbits as a larval host but also utilize several other plant families (Metcalf, 1979; Branson \& Krysan, 1981) and are more responsive to cucurbitacins than virgifera species group taxa (Metcalf et al., 1980; Tallamy et al., 1997). Meanwhile, virgifera group species while attracted to cucurbits show a wide range of variability, with taxa occurring outside the native range of Cucurbitaceae being less sensitive to cucurbitacins (Metcalf et al., 1980). Additionally, virgifera species group taxa are most likely unable to utilize cucurbits as larval hosts (Metcalf, 1986). This evidence indicates a possible evolutionary pattern. Assuming that complete association with Cucurbitaceae is the ancestral condition, we can estimate a divergence time scale for the Diabroticites examined in this study. For example, the average COI distance between Acalymma and Diabrotica species of $16.02 \%$ (calculated from Table 2) divided by an assumed sequence divergence rate of $1.71 \%$ per million years for Coleopteran COI sequences (Brower, 1994), yields an estimated divergence time of 9.37 million years ago (Ma) between these genera and 8.09 Ma (average distance $=13.84 \%$ ) between the Diabrotica species group. Both time frames are within Metcalf's (1979) hypothesized origin of a Diabroticite progenitor $20 \mathrm{Ma}$. The inclusion of Old World Aulocophora in future studies may also provide additional insight into the co-evolutionary relationship between these beetles and Cucurbitaceae as well as a time 
scale for the divergence of the different tribes, genera, and species within this entire group.

\section{Conclusions}

In conclusion, the molecular phylogeny obtained in this study supports morphological and allozyme based taxonomic assignments of Diabrotica at the species group level (virgifera and fucata) but differs from the allozyme study at lower taxonomic levels. Results are dependent upon both the taxa sampled and the resolving ability of the DNA sequences selected. Thus, only an initial view of Diabrotica phylogeny is presented in this work. It would be advantageous in future studies to include additional taxa in both the virgifera and fucata species groups as well as taxa from the third Diabrotica group, signifera, for which little information exists. Additional biological information is also necessary to assist in the interpretation of future results because little is known about most Diabrotica, particularly non-pest species. Given the inferred oligophagous (monophagous) characteristic of the virgifera species group (Krysan \& Smith, 1987) larval associations with grasses, an evolutionary study based on the phylogenetic relationships between the preferred larval hosts and/or female host-plant oviposition choices as well as the insects themselves would be of significant value. Correlating the results of such a study may provide insights as to why some species have become or have the potential to become pests. Beyond Diabrotica it would also be of value to expand phylogenetic studies into related genera to confirm whether the genus is indeed monophyletic. Krysan et al. (1989) raised this question because their allozyme based phenogram showed the fucata clade to be a sister group of the Diabroticite genera Acalymma and Paranapicaba. Likewise, it may be beneficial to expand phylogenetic examination across other genes such as other mitochondrial protein coding genes (Simon et al., 1994), nuclear ribosomal genes like $18 \mathrm{~S}$, or nuclear protein coding genes like elongation factor-1a (Caterino et al., 2000).

\section{Experimental procedures}

\section{Insects and DNA extraction}

Two individuals from beetles representing thirteen species of Diabrotica and two of Acalymma (outgroup) were collected from several localities for 
molecular analysis, thirty in total (Table 3). Specimens were identified using available dichotomous keys (Munroe \& Smith, 1980; Krysan, 1986; Krysan \& Smith, 1987) with representative vouchers verified by J. L. Krysan (USDAARS retired) and preserved in $95 \%$ ethanol or frozen $\left(-80^{\circ} \mathrm{C}\right)$. DNA was extracted using a modification of Black \& DuTeau's (1997) CTAB (hexadecyltrimethylammonium bromide) extraction protocol. The thorax and legs of individual beetles were ground in $500 \mathrm{ml} \mathrm{CTAB}$ buffer $(100 \mathrm{mM}$ Tris- $\mathrm{HCl}, 1.4 \mathrm{M} \mathrm{NaCl}, 0.02 \mathrm{M}$ EDTA ( $\mathrm{pH} 8.0), 2.0 \% \mathrm{CTAB}$, and $0.2 \% \mathrm{~b}-$ mercaptoethanol), and $5 \mathrm{ml}$ of $20 \mathrm{mg} / \mathrm{ml}$ of proteinase $\mathrm{K}$ was then added to each sample. After vortexing the mixture, samples were held at $65^{\circ} \mathrm{C}$ for $1 \mathrm{~h}$ vortexing at $20 \mathrm{~min}$ intervals. Samples were then cooled to room temperature before adding $15 \mathrm{ml}$ of $50 \mathrm{mg} / \mathrm{ml}$ RNase A, vortexing, and incubation at $37^{\circ} \mathrm{C}$ for $2.5 \mathrm{~h}$ (samples were vortexed at 30 min intervals). After incubation with RNase A, samples were centrifuged at $10000 \times \mathrm{g}$ for $5 \mathrm{~min}$ at room temperature. The supernatant was transferred to a fresh tube, where $500 \mathrm{ml}$ of a chloroform:isoamyl alcohol (24:1) was added. The mixture was vortexed and then centrifuged for $15 \mathrm{~min}$ at $10000 \mathrm{xg}$. The upper aqueous layer was then transferred to a fresh tube where DNA was precipitated with $500 \mathrm{ml}$ of $100 \%$ isopropanol $\left(-20^{\circ} \mathrm{C}\right)$. The mixture was gently inverted five times and placed at $4{ }^{\circ} \mathrm{C}$ for at least $2 \mathrm{~h}$ followed by centrifugation at $10000 \times \mathrm{g}$ at $4{ }^{\circ} \mathrm{C}$ for $30 \mathrm{~min}$. The supernatant was removed and the DNA pellet was washed twice with $700 \mathrm{ml}$ of $70 \%$ and $100 \%$ ethanol $\left(-20{ }^{\circ} \mathrm{C}\right)$, respectively. After the final wash and ethanol removal, the DNA pellet was air dried and resuspended overnight in $100 \mathrm{ml}$ of TE buffer (10 mM Tris-HCl, 1 mM EDTA ( $\mathrm{pH} 7.6)$ ).

\section{PCR amplification, cloning, and sequencing}

Polymerase chain reaction (PCR) was used to amplify two target regions in the mitochondrial and nuclear genomes: $\mathrm{COI}$ and ITS- 2, respectively. The COI gene was amplified in two overlapping fragments. The first fragment was amplified using the forward primer 5'GGAGGATTTGGAAATTGATTAGTTCC-3', named C1-J-1718 (Simon et al., 1994) and the reverse 5'-CCCGGTAAAATTAAAATATAAACTTC- 3', named C1-N-2191 in (Simon et al., 1994), which amplifies a central portion of the $\mathrm{COI}$ gene. The second overlapping $\mathrm{COI}$ fragment was amplified using the forward primer 5'-CAACATTTATTTTGATTTTTTGG-3' (named C1-J-2183 in Simon et al., 1994) and reverse 5'-TCCAATGCACTAATCTGCCATATT- 3' (named TL2-N-3014 in Simon et al., 1994), which amplifies the central and $3^{\prime}$ fragments of the COI gene along with a 5' portion of the t-RNA-Leu gene. $P C R$ of both COI gene fragments was done in $50 \mathrm{ml}$ reaction volumes 
containing $10 \mathrm{mM}$ Tris- $\mathrm{HCl}$ (pH 8.3), $50 \mathrm{mM} \mathrm{KCl}, 200 \mu \mathrm{M}$ dNTPs, $0.8 \mu \mathrm{M}$ of each primer, $1.25 \mathrm{U}$ of AmpliTaq polymerase (Perkin Elmer, Branchburg, NJ), $3.5 \mathrm{mM} \mathrm{MgCl}_{2}$, and $6 \mathrm{ml}$ of DNA template (diluted 1: 10 from the original $C T A B$ extraction). PCR of the reaction mixtures was done using either a GeneAmp PCR system 2400 or 9600 (Perkin Elmer, Branchburg, NJ) with the following temperature profile for both gene fragments: $94{ }^{\circ} \mathrm{C}$ for $2 \mathrm{~min}$; thirty-five cycles of $94{ }^{\circ} \mathrm{C}$ for $1 \mathrm{~min}, 52{ }^{\circ} \mathrm{C}$ for $30 \mathrm{~s}, 72{ }^{\circ} \mathrm{C}$ for $1 \mathrm{~min}$, and a final extension step of $72{ }^{\circ} \mathrm{C}$ for $8 \mathrm{~min}$. All amplifications had a negative control containing no DNA template. Amplification of ITS-2 was done using primers designed by Navajas et al. (1998). The forward primer 5'GGGTCGATGAAGAACGCAGC- $3^{\prime}$ and the reverse 5'ATATGCTTAAATTCAGCGGG- $3{ }^{\prime}$ are defined in the highly conserved $5.8 \mathrm{~S}$ and $28 \mathrm{~S}$ flanking rDNA regions, respectively. ITS-2 PCR amplifications were done in $50 \mu \mathrm{l}$ reaction volumes using the same reaction mixture proportions and thermocyclers described for $\mathrm{COI}$ gene amplification. The PCR temperature profile was also nearly identical, the exception was an annealing temperature of $55^{\circ} \mathrm{C}$.

Target PCR amplicons were purified via electrophoresis on low-melt 1.0\% TAE (0.04 M Tris-acetate, 0.001 M EDTA ( $\mathrm{pH} 8.0)$ ) agarose gels stained with ethidium bromide. Target DNA was briefly visualized over a UV transilluminator and excised from the gel. Purified PCR amplicons were then cloned directly into PCR 2.1 TOPO plasmid vector (TA cloning kit, Invitrogen Corp., Carlsbad, CA) using the manufacturer's protocol. Positive clones were sequenced in both directions using a dye primer sequencing protocol at the University of Nebraska, DNA Sequencing Core Research Facility (Lincoln, NE) using a Li-Cor model 4000 I DNA sequencer (Li-Cor, Inc. Lincoln, NE). Sequences were deposited in GenBank with corresponding accession numbers listed in Table 3.

\section{Phylogenetic construction}

COI and ITS-2 sequence data were aligned using the Clustal W algorithm (Thompson et al., 1994) as implemented in GCG 10.1 for UNIX (Genetics Computer Group Inc., Madison, WI) using default parameters. For the protein coding $\mathrm{COI}$ gene, sequences were also translated to amino acids (using GCG 10.1) based on invertebrate codon usage of mitochondrial DNA to assist in manual adjustments, which were made by eye. MacClade (version 3.08, Maddison \& Maddison, 1999) was used to compute sequence statistics such as variation among nucleotide positions within the codon as well nucleotide transformation frequencies. Genetic distances for individual data sets were estimated using Tamura-Nei distance (Tamura \& Nei, 1993). 
The data (individual and combined sequences) was also tested for phylogenetic structure that is significantly different from random using the PTP test (Faith, 1991) with 10000 random matrices and randomizing ingroup taxa using PAUP (v. 4.0b4a).

Both data sets (COI and ITS-2) were tested for heterogeneity to assess whether combining of $\mathrm{COI}$ and ITS-2 is appropriate for further phylogenetic analysis using the partition homogeneity test developed by Farris et al. (1994, 1995) and implemented within PAUP. Tests were performed with 1000 iterations.

Minimum evolution (ME), maximum parsimony (MP), and maximum likelihood (ML) phylogenetic analyses were conducted using the version of PAUP previously described. Each was performed using the heuristic search option employing step-wise addition with 100 random taxon addition sequence replicates. MP analysis was conducted using equal weight and with a weighting scheme of down-weighting third codon position transitions by a factor of 2 with respect to transversions (estimated by maximum likelihood on a neighbor-joining tree (Saitou \& Nei, 1987)). The model of DNA substitution for ME and ML was determined using the program MODELTEST (v. 3.04) (Posada \& Crandall, 1998). MODELTEST uses hierarchical likelihood ratio tests to determine the fit of General Time Reversible (GTR) family of substitution models (sixty-four total) that best fits the data. Parameters (base composition, substitution rates, proportion of invariable sites, and the gamma shape parameter) for the chosen model were estimated by maximum likelihood on the neighbour-joining algorithm (Saitou \& Nei, 1987). Node support for MP and ME analyses was assessed using 1000 bootstrap pseudoreplicates, due to computational constraints only 100 bootstrap replicates were performed for the ML analysis. Gaps were treated as missing data.

Acknowledgments - The authors would like to thank L. Chandler (USDA-ARS), M. Green (Novartis Corp.), S. Hanser (Zeneca Corp.), P. Vianna (EMBRAPA, Brazil), C. Hoffmann (Texas A \& M University), D. Isenhour (Monsanto Corp.), and A. Sagel (University of Nebraska) for their co-operation in providing specimens; Dr James Krysan (USDA-ARS, retired) provided assistance in specimen identification; $B$. Ratcliffe, A. Smith and M. Jameson the University of Nebraska-Lincoln, State Museum and A. Garcia, Plant Genetics Research Unit, USDA-ARS, Columbia, MO for the use of computers. We are also grateful to B. Hibbard, D. Stanley and K. Pruess, and three anonymous reviewers for helpful criticism of earlier drafts of the manuscript. This is paper is no. 13183, Journal Series, Nebraska Agricultural Division and contribution no. 1085, Department of Entomology, University of Nebraska-Lincoln. 


\section{References}

Black IV, W.C. and DuTeau N.M. (1997) RAPD-PCR and SSCP analysis for insect population genetic studies. In: The Molecular Biology of Insect Disease Vectors: a Methods Manual (J. M. Crampton, C. B. Beard and C. Louis, eds), 361- 373. Chapman \& Hall, New York.

Branson, T.F. and Krysan, J.L. (1981) Feeding and oviposition behavior and life cycle strategies of Diabrotica: an evolutionary view with implications for pest management. Environ Entomol 10: 826-831.

Brower, A.V.Z. (1994) Rapid morphological radiation and convergence among races of the butterfly Heliconius erato inferred from patterns of mitochondrial DNA evolution. Proc Natl Acad Sci USA 91: 6491-6495.

Brust, G.E. and Barbercheck, M.E. (1990) Effect of dietary cucurbitacin C on southern corn rootworm (Coleoptera: Chrysomelidae) egg survival. Environ Entomol 21: 1466- 1471.

Bull, J.J., Huelsenbeck, J.P., Cunningham, C.W., Swofford, D.L. and Waddell, P.J. (1993) Partitioning and combining data in phylogenetic analysis. Syst Biol 42: 384-397.

Camprag, D. and Baca, F. (1996) Diabrotica virgifera (Coleoptera, Chrysomelidae); a new pest of maize in Yugoslavia. Pestic Sci 45: 291-292.

Caterino, M.S., Cho, S. and Sperling, F.A.H. (2000) The current state of insect molecular systematics: a thriving tower of babel. Ann Rev Entomol 45: 1-54.

Caterino, M.S. and Sperling, F.A.H. (1999) Papilio phylogeny based on mitochondrial cytochrome oxidase I and II genes. Mol Phylogen Evol 11: 122137.

Chippindale, P.T., Davéé, V.K., Whitmore, D.H. and Robinson, J.V. (1999) Phylogenetic relationships of North American Damselflies of the genus Ischnura (Odonata: Zygoptera: Coenagrionidae) based on sequences of three mitochondrial genes. Mol Phylogenet Evol 11: 110-121.

Chuman, T., Guss, P.L., Doolittle, R.E., McLaughlin, J.R., Krysan, J.L., Schalk, J.M. and Tumlinson, J.H. (1987) Identification of female-produced sex pheromone from banded bucumber beetle, Diabrotica balteata LeConte (Coleoptera: Chrysomelidae). J Chem Ecol 13: 1601-1616.

Cinereski, J.E. and Chiang, H.C. (1968) The patterns and movements of adults of the northern corn rootworms inside and outside of corn fields. J Econ Entomol 61: 1531-1536.

Depaquit, J., Ferté, H., Léger, N., Killick-Kendrick, R., Rioux, J.-A., Killick-Kendrick, M., Hanafi, H.A. and Gobert, S. (2000) Molecular systematics of the Phlebotomine sandflies of the subgenus Paraphlebotomus (Diptera: Psychodidae, Phlebotomus) based on ITS2 rDNA sequences. Hypothesis of dispersion and speciation. Insect Mol Biol 9: 293-300.

Eben, A. (1999) New information on the natural history of Diabrotica scutellata Jacoby (Chrysomelidae: Luperini). Coleop Bull 53: 186. 
Eben, A. and Barbercheck, M.E. (1996) Field observations on host plant associations and natural enemies of diabroticite beetles (Chrysomelidae: Luperini) in Veracruz, Mexico. Acta Zool Mex 67: 47-65.

Eben, A. and Barbercheck, M.E. (1997) Host plant and substrate effects on mortality of southern corn rootworm from entomopathogenic nematodes. Biol Cont 8: 89-96.

Faith, D.P. (1991) Cladistic permutation tests for monophyly and nonmonophyly. Syst Zool 40: 366-375.

Farris, J.S., Käällersjöö, M., Kluge, A.G. and Bult, C. (1994) Testing significance of incongruence. Cladistics 10: 315-319.

Farris, J.S., Käällersjöö, M., Kluge, A.G. and Bult, C. (1995) Constructing a significance test for incongruence. Syst Biol 44: 570-572.

Ferguson, J.E. and Metcalf, R.L. (1985) Cucurbatacins: Plant derived defense compounds for diabroticites (Coleoptera: Chrysomelidae). J Chem Ecol 11: 311-318.

Ferguson, J.E., Metcalf, R.L. and Fisher, D.C. (1985) Distribution and fate of cucurbitacin B in five species of diabroticites. J Chem Ecol 11: 1307-1321.

Giordano, R., Jackson, J.J. and Robertson, H.M. (1997) The role of Wolbachia bacteria in reproductive incompatibilities and hybrid zones of Diabrotica beetles and Gryllus crickets. Proc Natl Acad Sci USA 94: 11439-11444.

Golden, K.L. (1990) Cuticular hydrocarbons of sibling species Diabrotica longicornis (Say) and D. barberi Smith and Lawrence: Use as chemotaxonomic characters for species separation and study of population variation. MSc Thesis, The University of Nebraska, USA.

Gu, X., Fu, Y.-X. and Li, W.-H. (1995) Maximum likelihood estimation of the heterogeneity of substitution rate among nucleotide sites. Mol Biol Evol 12: 546-557.

Guss, P.L., Sonnet, P.E., Carney, R.L., Branson, T.F. and Tumlinson, J.H. (1984) Response of Diabrotica virgifera virgifera, D. v. zeae, and D. porracea to stereoisomers of 8-methyl-2-decyl propanoate. J Chem Ecol 10: 1123-1131.

Guss, P.L., Sonnet, P.E., Carney, R.L., Tumlinson, J.H. and Wilkin, P.J. (1985) Response of northern corn rootworm, Diabrotica barberi Smith and Lawrence, to stereoisomers of 8-methyl-2-decyl propanoate. J Chem Ecol 10: 21-26.

Guss, P.L., Carney, R.L., Sonnet, P.E. and Tumlinson, J.H. (1983a) Stereospecific sex attractant for Diabrotica cristata (Harris) (Coleoptera: Chrysomelidae). Environ Entomol 12: 1296-1297.

Guss, P.L., Tumlinson, J.H., Sonnet, P.E. and McLaughlin, J.R. (1983b) Identification of a female produced sex pheromone from the southern corn rootworm, Diabrotica undecimpunctata howardi Barber. J Chem Ecol 9: 1363-1375.

Guss, P.L., Tumlinson, J.H., Sonnet, P.E. and Proveaux, A.T. (1982) Identification of a female produced sex pheromone of the western corn rootworm. J Chem Ecol 8: 545-556.

Hillis, D.M. and Bull, J.J. (1993) An empirical test of bootstrapping as a method for assessing confidence in phylogenetic analysis. Syst Biol 42: 182-192. 
Hillis, D.M., Huelsenbeck, J.P. and Cunningham, C.W. (1994a) Application and accuracy of molecular phylogenies. Science 264: 671-677.

Hillis, D.M., Huelsenbeck, J.P. and Swofford, D.L. (1994b) Hobgoblin of phyogenetics? Nature 369: 671-677.

Huang, Y., Ortí, G., Sutherlin, M., Duhachek, A. and Zera, A. (2000) Phylogenetic relationships of North American field crickets inferred from mitochondrial DNA data. Mol Phylogenet Evol 17: 48-57.

Huelsenbeck, J.P., Bull, J.J. and Cunningham, C.W. (1996) Combining data in phylogenetic analysis. Trends Ecol Evol 11: 152-158.

Koulianos, S. (1999) Phylogenetic relationships of the bumblebee subgenus Pyrobombus (Hymenoptera: Apidae) inferred from mitochondrial cytochrome B and cytochrome oxidase I sequences. Ann Entomol Soc Am 92: 355-358.

Krysan, J.L. (1982) Diapause in the nearctic species of the virgifera group of Diabrotica: evidence for tropical orgin and temperate adaptations. Ann Entomol Soc Am 75: 136-142.

Krysan, J.L. (1986) Introduction: biology, distribution, and identification of pest Diabrotica. In: Methods for the Study of Pest Diabrotica. (J. L. Krysan and T. A. Miller, eds), pp. 1-23. Springer-Verlag, New York.

Krysan, J.L. (1999) Selected topics in the biology of Diabrotica. In: Advances in Chrysomelidae Biology (M. L. Cox, ed.), pp. 479-513. Backhuys Publishers, Leiden, The Netherlands.

Krysan, J.L. and Guss, P.L. (1978) Barriers to hybridization between Diabrotica virgifera and $D$. longicornis barberi (Coleoptera: Chrysomelidae). Ann Entomol Soc Am 71: 931-934.

Krysan, J.L., McDonald, I.C. and Tumlinson, J.H. (1989) Phenogram based on allozymes and its relationship to classical biosystematics and pheromone structure among eleven Diabroticites (Coleoptera: Chrysomelidae). Ann Entomol Soc Am 82: 574-581.

Krysan, J.L. and Smith, R.F. (1987) Systematics of the virgifera species group of Diabrotica (Coleoptera: Chrysomelidae: Galerucinae). Entomography 5: 375484.

Krysan, J.L., Smith, R.F. and Guss, P.L. (1983) Diabrotica barberi (Coleoptera: Chrysomelidae) elevated to species rank based on behavior, habitat choice, morphometrics, and geographical variation of color. Ann Entomol Soc Am 76: 197-204.

Krysan, J.L., Wilkin, P.H., Tumlinson, J.H., Sonnet, P.E., Carney, R.L. and Guss, P.L. (1986) Responses of Diabrotica lemniscata and D. longicornis (Coleoptera: Chrysomelidae) to stereoisomers of 8-methyl-2-decyl-propanoate and studies on the pheromone of D. longicornis. Ann Entomol Soc Am 79: 742-746.

Kuperus, W.R. and Chapco, W. (1994) Usefulness of internal transcribed spacer regions of ribosomal DNA in Melanopline (Orthoptera: Acrididae) systematics. Ann Entomol Soc Am 87: 751-754.

Lanave, C., Preparata, C., Saccone, C. and Serio, G. (1984) A new method for calculating evolutionary substitution rates. J Mol Evol 20: 86-93. 
Lunt, D.H., Ibrahim, K.M. and Hewitt, G.M. (1998) mtDNA phylogeography and postglacial patterns of subdivision in the meadow grasshopper Chorthippus parallelus. Heredity 80: 633-641.

Lunt, D.H., Zhang, D.-X., Szymura, J.M. and Hewitt, G.M. (1996) The insect cytochrome oxidase I gene: Evolutionary patterns and conserved primers for phylogenetic studies. Insect Mol Biol 5: 153-165.

Maddison, W.P. and Maddison, D.R. (1999) Macclade: Analysis of Phylogeny and Character Evolution, Version 3.08. Sinauer Associates, Sunderland, Massachusetts, USA.

Metcalf, R.L. (1979) Plants, chemicals, and insects: Some aspects of coevolution. Bull Entomol Soc Am 25: 30-35.

Metcalf, R.L. (1986) Coevolutionary adaptations of rootworm beetles (Coleoptera: Chrysomelidae) to cucurbitacins. J Chem Ecol 12: 1109-1124.

Metcalf, R.L., Ferguson, J.E., Lampman, R. and Anderson, J.F. (1987) Dry cucurbitacin-containing baits for controlling Diabroticite beetles (Coleoptera: Chrysomelidae). J Econ Entomol 80: 870-875.

Metcalf, R.L., Metcalf, R.A. and Rhodes, A.M. (1980) Cucurbitacins as kairomones for diabroticite beetles. Proc Natl Acad Sci USA 77: 3769-3772.

Meyer, A. (1994) Shortcomings of the cytochrome b gene as a molecular marker. Trends Ecol Evol 9: 278-280.

Miller, B.R., Crabtree, M.B. and Savage, H.M. (1996) Phylogeny of fourteen Culex mosquito species, including the Culex pipiens complex, inferred from internal transcribed spacers of ribosomal DNA. Insect Mol Biol 5: 93-107.

Miyamoto, M.M. and Fitch, W.M. (1995) Testing species phylogenies and phylogenetic methods with congruence. Syst Biol 44: 64-76.

Munroe, D.D. and Smith, R.F. (1980) A revision of the systematics of Acalymma sensu stricto Barber (Coleoptera: Chrysomelidae) from North America including Mexico. Mem Entomol Soc Can 112: 1-92.

Navajas, M., Lagnel, J., Gutierrez, J. and Boursot, P. (1998) Species-wide homogeneity of nuclear ribosomal ITS-2 sequences in the spider mite Tetranychus urticae contrasts with extensive mitochondrial COI polymorphism. Heredity 80: 742-752.

Nishida, R. and Fukami, H. (1990) Sequestration of distasteful compounds by some pharmacophagous insects. J Chem Ecol 16: 151-164.

Paskewitz, S.M., Wesson, D.M. and Collins, F.H. (1993) The internal transcribed spacers of ribosomal DNA in five members of the Anopheles gambiae species complex. Insect Mol Biol 2: 247-257.

Pitre, H.N. Jr and Kantack E.J. (1962) Biology of the banded cucumber beetle, Diabrotica balteata, in Louisiana. J Econ Entomol 55: 904-906.

Porter, C.H. and Collins, F.H. (1991) Species-diagnostic differences in a ribosomal DNA internal transcribed spacer from the sibling species Anopheles freeborni and Anopheles hermsi (Diptera: Culicidae). Am J Trop Med Hyg 45: 271-279.

Posada, D. and Crandall, K.A. (1998) MODELTEST: Testing the model of DNA substitution. Bioinformatics 14: 817-818. 
de Queiroz, A., Donoghue, M.J. and Kim, J. (1995) Separate versus combined analysis of phylogenetic evidence. Annu Rev Ecol Syst 26: 657-681.

Saba, F. (1970) Host plant spectrum and temperature limitations of Diabrotica balteata. Can Entomol 102: 684-691.

Saitou, N. and Nei, M. (1987) The neighbor-joining method: A new method for reconstructing trees. Mol Biol Evol 4: 406-425.

Schilthuizen, M., Nordlander, G., Stouthamer, R. and Van Alphen, J.J.M. (1998) Morphological and molecular phylogenetics in the genus Leptopilina (Hymenoptera: Cynipoidea: Eucoilidae). Syst Entomol 23: 253-264.

Simon, C., Frati, F., Beckenbach, A., Crespi, B., Liu, H. and Flook, P. (1994) Evolution, weighting, and phylogenetic utility of mitochondrial gene sequences and a compilation of conserved polymerase chain reaction primers. Ann Entomol Soc Am 87: 651-701.

Smith, R.F. (1966) Distributional patterns of selected western North American insects: The distribution of Diabroticites in western North America. Bull Entomol Soc Am 12: 108-110.

Smith, R.F. and Lawrence, J.F. (1967) Clarification of the type specimens of Diabroticites (Coleoptera, Chrysomelidae, Galerucinae). Univ Calif Pub Entomol 45: 1-174.

Smith, R.F. and Michelbacher, A.E. (1949) The development and behavior of populations of Diabrotica 11-punctata in foothill areas of California. Ann Entomol Soc Am 42: 497-510.

Tallamy, D.W., Gorski, P.M. and Pesek, J.D. (1997) Intra- and interspecific genetic variation in the gustatory perception of cucurbitacins by Diabroticite rootworms (Coleoptera: Chrysomelidae). Environ Entomol 26: 1364-1372.

Tallamy, D.W., Stull, J., Ehresman, N.P., Gorski, P.M. and Mason, C.E. (1998) Sequestered cucurbitacins and pathogenicity of Metarhizium anisopliae (Moniliales: Moniliaceae) on spotted cucumber beetle eggs and larvae (Coleoptera: Chrysomelidae). Environ Entomol 27: 366-372.

Tamura, K. and Nei, M. (1993) Estimation of the number of nucleotide substitutions in the control region of mitochondrial DNA in humans and chimpanzees. Mol Biol Evol 10: 512-526.

Thompson, J.D., Higgins, D.G. and Higgins, T.J. (1994) Clustal W: Improving the sensitivity of progressive sequence alignment through sequence weighting, position gap penalties and weight matrix choice. Nuc Acids Res 22: 4673-4680.

Vogler, A.P. and DeSalle, R. (1994) Evolution and phylogenetic information content of the ITS-1 region in the tiger beetle Cicindela dorsalis. Mol Biol Evol 11: 393405.

Vogler, A.P. and Welsh, A. (1997) Phylogeny of North American Cicindela tiger beetles inferred from multiple mitochondrial DNA sequences. Mol Phylogenet Evol 8: 225-235.

Weissling, T.J. and Meinke, L.J. (1991) Semiochemical-insecticidal bait placement and vertical distribution of corn rootworm (Coleoptera: Chrysomelidae) adults: Implications for management. Environ Entomol 20: 945-952. 
Weissling, T.J., Meinke, L.J., Trimmell, D. and Golden, K.L. (1989) Behavioral responses of Diabrotica adults to plant-derived semiochemicals encapsulated

Wilcox, J.A. (1965) A synopsis of the North American Galerucinae (Coleoptera: Chrysomelidae). New York State Mus Sci Serv Bull 400: 1-226.

Wilcox, J.A. (1972) Coleopterorum Catalogus Supplementa, pp. 296- 431. In Pars 78. Fasc 2. (editio seconda). (Galerucinae: Luperini: Diabroticina).

Yang, Z. (1994) Maximum likelihood phylogenetic estimation from DNA sequences with variable rates over sites: approximate methods. J Mol Evol 39: 306-314.

Yaro, N. and Krysan, J.L. (1986) Host relationships of Diabrotica cristata (Coleoptera: Chrysomelidae). Entomol News 97: 11-16. 


\section{Figures}

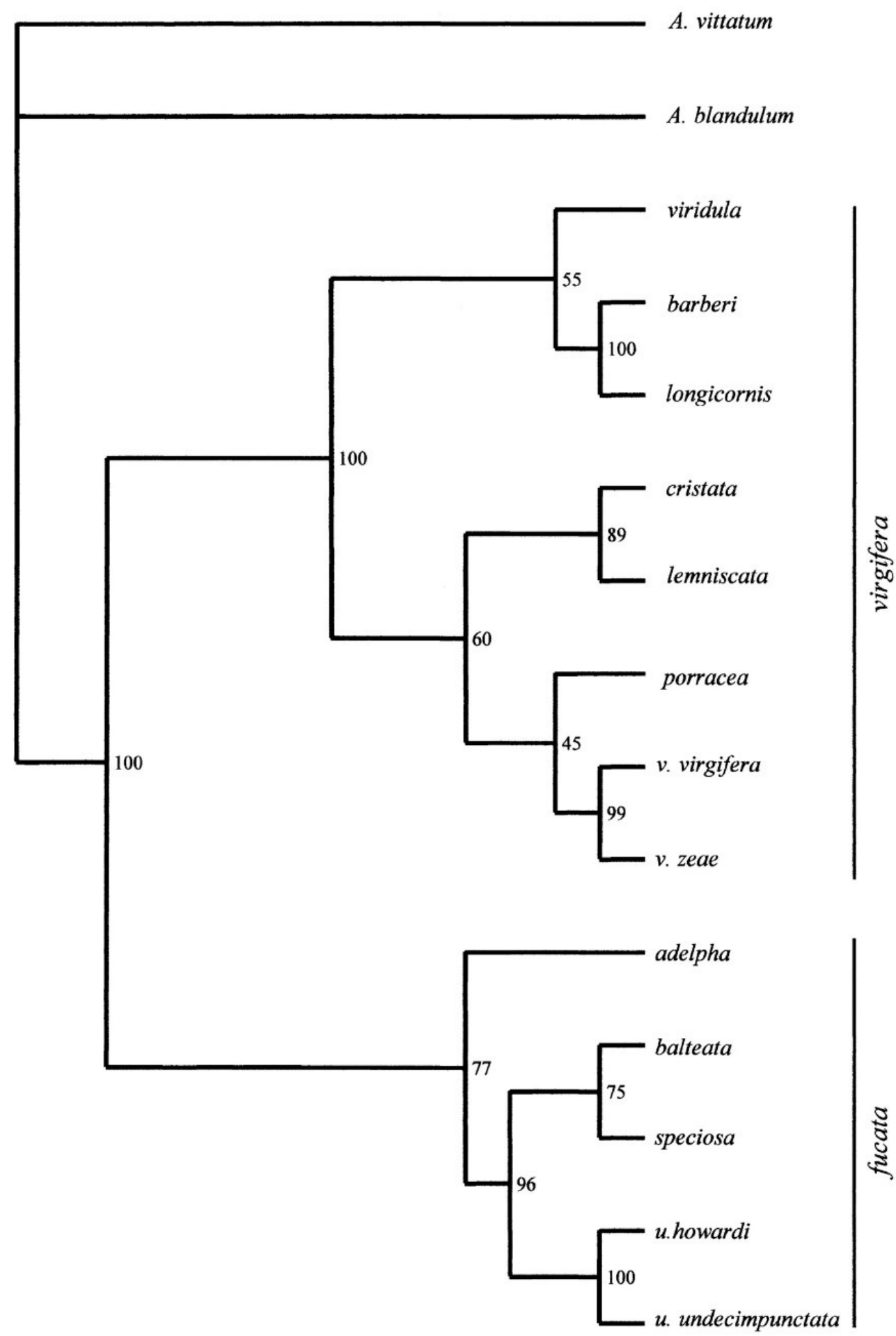

Figure 1. Unweighted parsimony tree (1154 steps; Consistency Index $=0.609$, Retention Index 0.584 ) resulting from analysis of combined COI and ITS-2 data sets (1682 characters). Bootstrap percentages of 1000 replicates are shown above the branches. Morphological species group labels are shown to illustrate taxonomic congruence. 


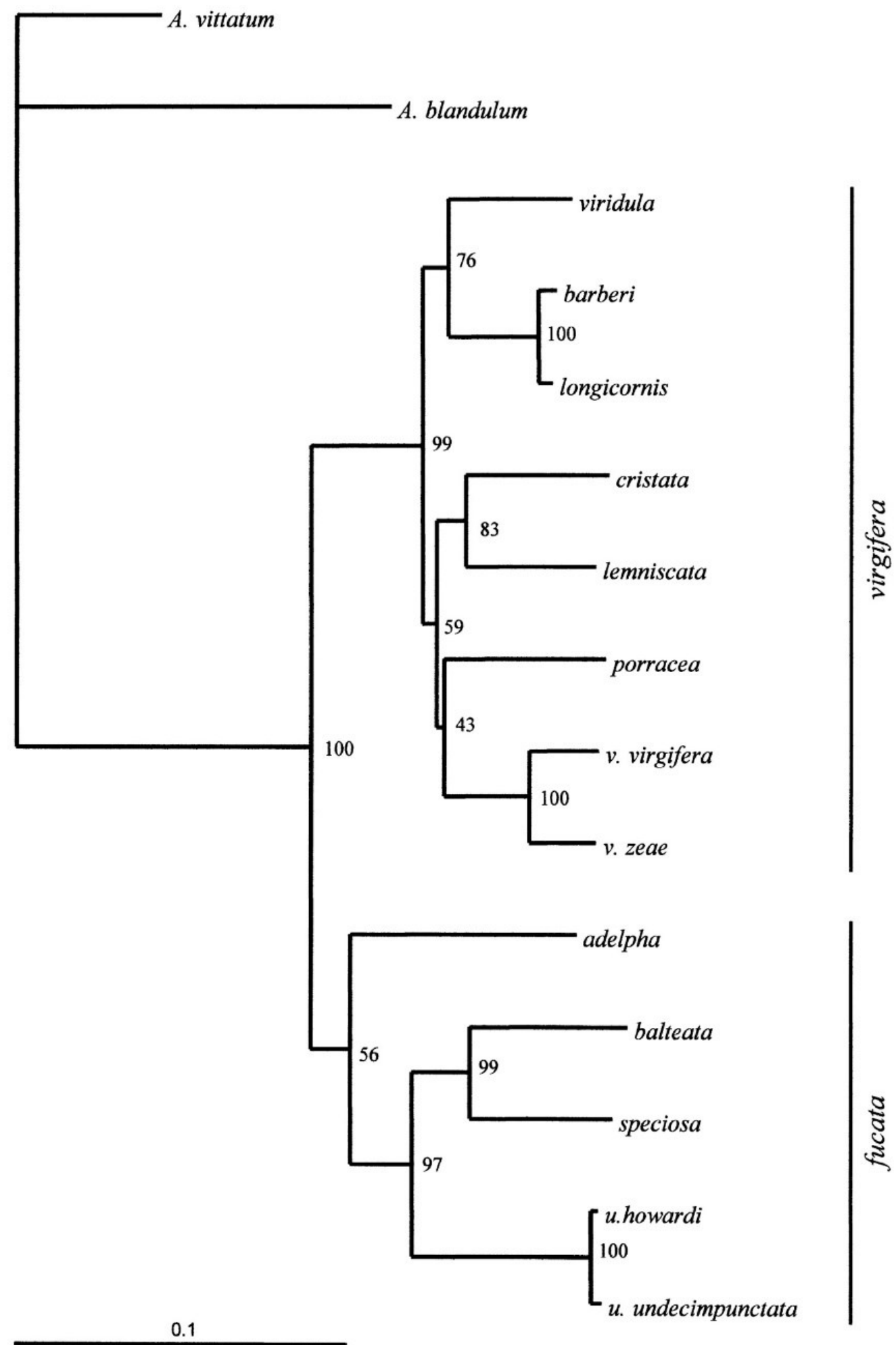

Figure 2. Minimum evolution tree for the combined COI and ITS-2 data sets (1682 characters) under the GTR + I + G model (see results section for parameter values). Bootstrap percentages of 1000 replicates are shown above the branches. Branch lengths are proportional to inferred distances. Morphological species group labels are shown to illustrate taxonomic congruence. 


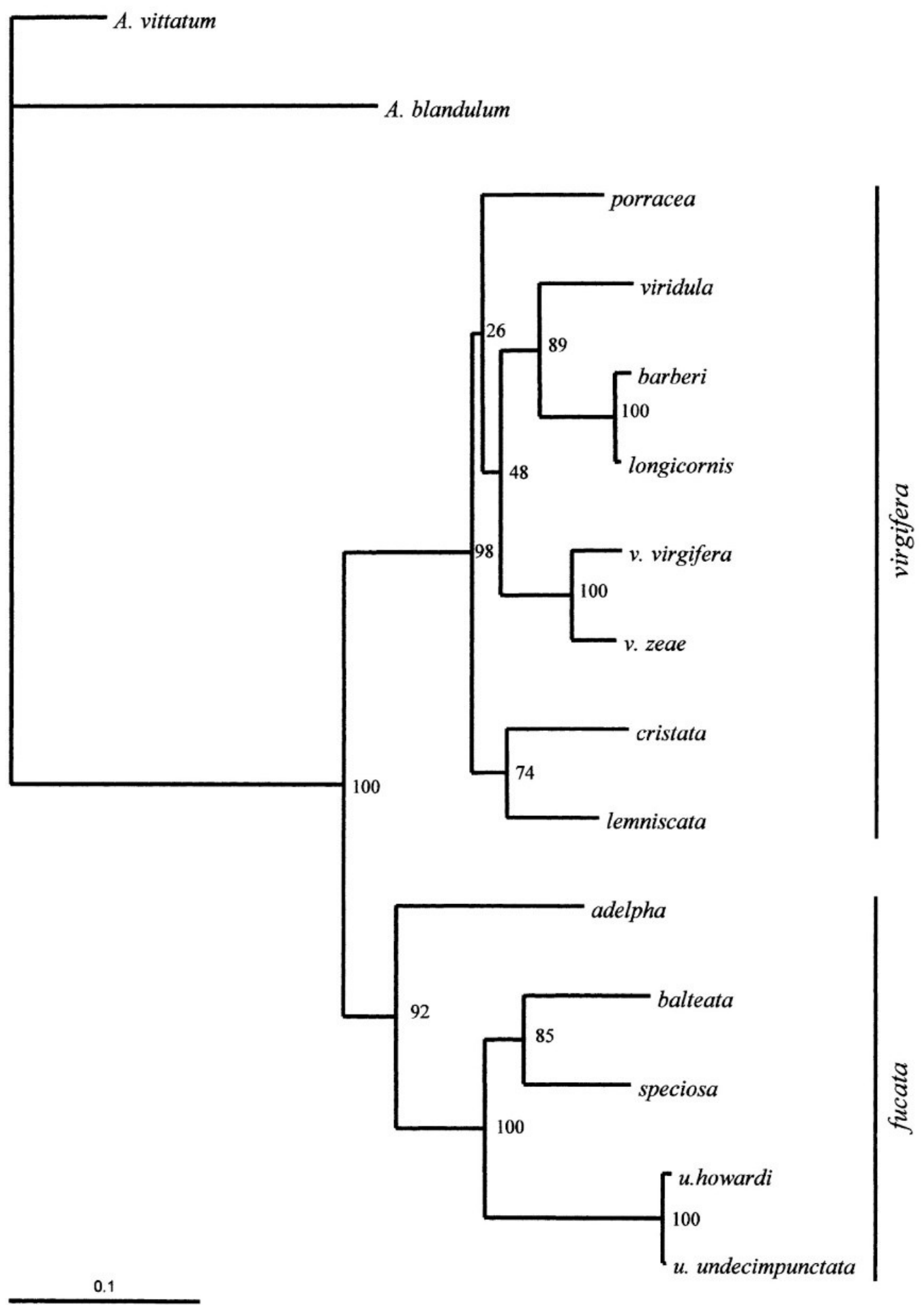

Figure 3. Maximum-likelihood tree (Ln likelihood $=-7539.79$ ) for the combined COI and ITS-2 data sets (1682 characters) under the GTR + I + G model (see results section for parameter values). Bootstrap percentages of 100 replicates are shown above the branches. Branch lengths are proportional to inferred distances. Morphological species group labels are shown to illustrate taxonomic congruence. 
Table 1. Base composition for $\mathrm{COI}$ and ITS sequences.

\begin{tabular}{|c|c|c|c|c|c|c|}
\hline \multirow{2}{*}{$\begin{array}{l}\text { Codon } \\
\text { nucleotide } \\
\text { position }\end{array}$} & \multicolumn{4}{|l|}{ Base composition } & \multirow[b]{2}{*}{ variable sites } & \multirow{2}{*}{$\begin{array}{l}\% \\
\text { Indels }\end{array}$} \\
\hline & A & C & G & $\mathrm{T}$ & & \\
\hline COI pos. 1 & 27.95-28.93 (28.45) & $13.41-15.03(14.55)$ & $25.06-26.20(25.83)$ & 29.84-32.27 (31.18) & 18.18 & 1 \\
\hline COI pos. 2 & $16.40-17.05$ (16.82) & $23.18-23.69$ (23.42) & $16.14-16.63(16.34)$ & $43.18-43.74(43.42)$ & 3.86 & 1 \\
\hline COI pos. 3 & $44.09-48.29(46.03)$ & $5.47-8.86(7.00)$ & $1.37-5.45$ (3.52) 41. & $36-44.87(43.45)$ & 74.09 & 1 \\
\hline All COI sites & $29.70-31.29(30.43)$ & 14.39-15.79 (14.99) & $14.58-15.83(15.23)$ & $38.48-39.70(39.35)$ & 32.05 & 1 \\
\hline All ITS-2 sites & $28.86-33.14(32.32)$ & 12.99-15.14 (13.93) & $17.16-21.43(19.15)$ & $33.81-35.59(34.60)$ & 21.55 & $47^{*}$ \\
\hline
\end{tabular}

* Nucleotide sites that had an indel with respect to A. vittatum. Base composition ranges across taxa are given with means in parentheses.

Table 2. Genetic distances based on Tamura and Nei's method; ITS-2 (above diagonal) and COI (below diagonal).

\begin{tabular}{|c|c|c|c|c|c|c|c|c|c|c|c|c|c|c|c|}
\hline & \multicolumn{2}{|c|}{ Acalymma } & \multicolumn{8}{|c|}{ virgifera species group } & \multicolumn{4}{|c|}{ fucata species group } & \multirow[b]{2}{*}{15.} \\
\hline & 1. & 2. & 3. & 4. & 5. & 6. & 7. & 8. & 9. & 10. & 11. & 12. & 13. & 14. & \\
\hline 1. A. blandulum & & 0.091 & 0.223 & 0.223 & 0.226 & 0.222 & 0.227 & 0.232 & 0.229 & 0.237 & 0.202 & 0.202 & 0.211 & 0.215 & 0.192 \\
\hline 2. A. vittatum & 0.126 & & 0.164 & 0.164 & 0.162 & 0.166 & 0.164 & 0.168 & 0.165 & 0.168 & 0.147 & 0.144 & 0.154 & 0.162 & 0.131 \\
\hline 3. D. cristata & 0.177 & 0.145 & & 0.011 & 0.023 & 0.026 & 0.026 & 0.029 & 0.023 & 0.032 & 0.074 & 0.064 & 0.079 & 0.085 & 0.055 \\
\hline 4. D. lemniscata & 0.184 & 0.146 & 0.088 & & 0.020 & 0.023 & 0.023 & 0.026 & 0.020 & 0.029 & 0.071 & 0.061 & 0.075 & 0.082 & 0.055 \\
\hline 5. D. barberi & 0.162 & 0.136 & 0.107 & 0.098 & & 0.003 & 0.009 & 0.012 & 0.006 & 0.027 & 0.068 & 0.058 & 0.062 & 0.069 & 0.055 \\
\hline 6. D. longicornis & 0.162 & 0.136 & 0.107 & 0.094 & 0.011 & & 0.012 & 0.015 & 0.009 & 0.030 & 0.065 & 0.055 & 0.059 & 0.066 & 0.052 \\
\hline 7. D. v. zeae & 0.179 & 0.141 & 0.090 & 0.082 & 0.093 & 0.090 & & 0.003 & 0.009 & 0.029 & 0.071 & 0.064 & 0.072 & 0.079 & 0.055 \\
\hline 8. D. v. virgifera & 0.176 & 0.136 & 0.105 & 0.103 & 0.092 & 0.089 & 0.047 & & 0.012 & 0.032 & 0.074 & 0.067 & 0.075 & 0.082 & 0.058 \\
\hline 9. D. viridula & 0.170 & 0.135 & 0.105 & 0.104 & 0.078 & 0.075 & 0.102 & 0.098 & & 0.026 & 0.077 & 0.068 & 0.072 & 0.079 & 0.058 \\
\hline 10. D. porracea & 0.179 & 0.147 & 0.113 & 0.091 & 0.089 & 0.090 & 0.096 & 0.089 & 0.095 & & 0.081 & 0.071 & 0.085 & 0.092 & 0.055 \\
\hline 11. D. speciosa & 0.181 & 0.151 & 0.146 & 0.138 & 0.143 & 0.139 & 0.146 & 0.139 & 0.142 & 0.157 & & 0.009 & 0.030 & 0.037 & 0.022 \\
\hline 12. D. balteata & 0.184 & 0.156 & 0.142 & 0.148 & 0.141 & 0.141 & 0.150 & 0.144 & 0.146 & 0.152 & 0.098 & & 0.021 & 0.027 & 0.013 \\
\hline 13. D. u. howardi & 0.183 & 0.149 & 0.138 & 0.134 & 0.124 & 0.125 & 0.138 & 0.139 & 0.125 & 0.133 & 0.112 & 0.118 & & 0.006 & 0.022 \\
\hline 14. D. u. undecimpunctata & 0.182 & 0.146 & 0.140 & 0.133 & 0.124 & 0.125 & 0.134 & 0.138 & 0.125 & 0.134 & 0.106 & 0.114 & 0.005 & & 0.029 \\
\hline 15. D. adelpha & 0.170 & 0.151 & 0.140 & 0.137 & 0.132 & 0.133 & 0.141 & 0.141 & 0.145 & 0.147 & 0.122 & 0.135 & 0.136 & 0.133 & \\
\hline
\end{tabular}


Table 3. Collection sites for Diabrotica and Acalymma (outgroup) specimens examined with corresponding sequence accession numbers.

\section{virgifera clade}

D. barberi Smith and Lawrence

D. cristata (Harris)

D. lemniscata LeConte

D. longicornis (Say)

D. porracea Harold

D. virgifera virgifera LeConte

D. virgifera zeae Krysan and Smith

D. viridula (Fabricius)

\section{fucata clade}

D. adelpha Harold

D. balteata LeConte

D. speciosa Germar

D. undecimpunctata howardi Barber

D. undecimpunctata undecimpunctata Mannerheim

\section{Outgroup}

A. blandulum (LeConte)

A. vittatum (Fabricius)
USA: lowa: Clinton County on Zea mays L.

USA: Nebraska: 9-Mile Prairie, Lancaster County on Andropogon gerardii Vitman

USA: New Mexico- near Kit Carson Museum, Colfax County on

Curcurbita foetidissima HBK

USA: Nebraska: Nuckolls County on Curcurbita foetidissima HBK

Panama: Cordillera on Zea mays $L$

USA: Kansas: Wallace County on C. foetidissima HBK

USA: Texas: Bell County on Zea mays L.

Panama: Cordillera on Zea mays L.

Panama: Chiriqui on Glycine sp.

USA: Florida: Indian River County laboratory colony host unknown

Brazil: Sete Lagoas on Glycine max L. AF278554

USA: New Mexico: near Kit Carson Museum, Colfax County on

Curcurbita foetidissima HBK

USA: California: Alameda County laboratory colony, host unknown

USA: Nebraska: Nuckolls County on Curcurbita foetidissima HBK

USA: Nebraska: Lancaster County on Curcurbita pepo L.

$\begin{array}{ll}\text { COI } & \text { ITS-2 } \\ \text { AF278544 } & \text { AF278559 } \\ \text { AF278545 } & \text { AF278560 } \\ \text { AF278546 } & \text { AF278561 } \\ \text { AF278547 } & \text { AF278562 } \\ \text { AF278548 } & \text { AF278563 } \\ \text { AF278549 } & \text { AF278564 } \\ \text { AF278550 } & \text { AF278565 } \\ \text { AF278551 } & \text { AF278566 } \\ & \\ \text { AF278552 } & \text { AF278567 } \\ \text { AF278553 } & \text { AF278568 } \\ \text { AF278569 } & \text { AF278570 } \\ \text { AF278555 } & \\ \text { AF278556 } & \text { AF278571 }\end{array}$

AF278543 AF278558

AF278542 AF278557 